(Orgs.). Diálogos na educação de jovens e adultos. Belo Horizonte: Autêntica, 2006.

FERREIRA, A. B. de H. Dicionário online de Português. São Paulo, SP, Saraiva 2016 Disponível em: 〈https://dicionariodoaurelio.com/evasao〉. Acesso em 16 de maio de 2017.

BRASIL, Ministério Público do Estado do Espirito Santo. Lei de Diretrizes e Bases da Educação Nacional. 2.ed. Espirito Santo: Vitória, 1996. Disponível em: <http://portal.mec.gov.br/seesp/arquivos/pdf/lei9394_Idbn2.pdf> Acesso em: 18 maio 2017.

. Ministério da Educação. Departamento. Secretária. Educação de jovens e adultos: parâmetros em ação. Brasília, DF,1988.

. Ministério da Educação. Educação de jovens e adultos: parâmetros em ação. Brasília, DF, 1999.

DUK, C. Educar na diversidade: material de formação docente. Brasília: MEC, SEESP. 2006.

Disponível

em:

<http://portal.mec.gov.br/seesp/arquivos/pdf/educarnadiversidade2006.pdf.>. Acesso em: 26 jun. 2017.

FORTUNATO, I. Educação de jovens e adultos. Sorocaba: REU, 2010.

FREIRE, P. A importância do ato de ler. 6. ed. Rio de Janeiro: Paz e Terra, 2002. Disponível em: <http;//www.clicrbs.com.br/pdf/11617839.pdf.>. Acesso em: 12 jun. 2017.

FREIRE, P. Educação como prática da liberdade. 26. ed. Rio de Janeiro: Paz e Terra, 2005. Disponível em: <http://www.clicrbs.com.br/pdf/11617839.pdf.>. Acesso em: 12 jun. 2017.

FREIRE, P. Pedagogia da autonomia. 13. ed. São Paulo: Paz e Terra, 1996. Disponível em: <http://www.apeoesp.org.br/sistema/ck/files/4\%20Freire_P_\%20Pedagogia\%20da\%20autonomia.pdf.>. Acesso em: 12 jun. 2017. FREIRE, P. Política e Educação: ensaios. São Paulo: Cortez, 1997.

GADOTTI, M. Educação de Jovens e Adultos: um cenário possível para o Brasil. São Paulo: Paiva, 2017.

GUIMARÃES, M. T. C.; DUARTE, A. J. Educação de Jovens e Adultos (EJA): Escola e o Trabalho na Mediação entre o Presente e o Futuro. ANPE, Caxambu, MG. 
2007. Disponível em: <http://www.anped.org.br/reunioes/31ra/1trabalho/GT18-3968-Int.pdf>. Acesso em: 19 out. 2012.

MAGALHÃES, V. N. S. A evasão escolar de jovens e adultos. 2013. $41 \mathrm{f}$. Tese

(Doutorado) - Curso de Pedagogia, Universidade de Brasília, Brasília, DF, 2013.

MORIN, E. Os sete saberes necessários à educação do futuro. 2. ed. São Paulo: Cortez, 2000.

OLIVEIRA, I. B. Reflexões acerca da organização curricular e das práticas pedagógicas na EJA. Curitiba: UFPR., 2007.

SOARES, L. J. G. Aas políticas de EJA e as necessidades de aprendizagem dos jovens e adultos. In: RIBEIRO, Vera Masagão (org). Educação de jovens e adultos: novos leitores, novas leituras. Campinas: Mercado das Letras, 2001.

\section{AGRADECIMENTOS}

Agradeço ao meu Deus pela sabedoria e força que me deste para superar os desafios, aos meus pais pelo apoio e entendimento aos momentos em que estive ausente para me dedicar aos estudos, aos meus irmãos, às Professoras e Professores, que lado a lado me acompanharam e orientaram, dando direcionamento para qual caminho seguir, à todos os professores do curso, que contribuíram para minha formação e incentivaram todos os pequenos projetos ampliando os conhecimentos adquiridos em sala, e à todos que contribuíram de forma direta ou indiretamente na conclusão de mais esta etapa de minha vida e que mesmo não citados aqui não deixam de merecer meu agradecimento. 


\section{GT 06}

\section{Alfabetização, infância e cotidiano escolar}




\title{
CRIANÇAS NO COTIDIANO ESCOLAR DA ALFABETIZAÇÃO INICIAL: REFLEXÕES SOBRE POLÍTICAS PÚBLICAS, INFÂNCIAS E APRENDIZAGENS
}

\author{
Mariane Éllen da Silva ${ }^{12}$ \\ Escola de Educação Básica da UFU \\ mariane.eseba@ufu.br \\ Myrtes Dias da Cunha ${ }^{13}$ \\ Faculdade de Educação da UFU \\ myrtesufu@gmail.com
}

Resumo: O presente estudo tece algumas reflexões sobre a pesquisa referente ao Pacto Nacional pela Alfabetização na Idade Certa (PNAIC), política pública do governo federal, voltada para a formação de professores alfabetizadores ( $1 .^{\circ}$ ao $3 .^{\circ}$ ano), que intenta assegurar que todas as crianças brasileiras estejam alfabetizadas até os 8 anos de idade; ao final do $3^{\circ}$ ano do ensino fundamental. Tem por objetivo compreender como esse Programa, por meio dos cadernos em alfabetização em língua portuguesa da formação continuada de professores alfabetizadores, projeta a criança e seu aprendizado da leitura e escrita no $1^{\circ}$ ano do Ensino Fundamental. Desse modo, abordaremos em nossas análises a organização do cotidiano escolar nas turmas de $1 .^{\circ}$ ano do ensino fundamental, buscando compreender como a organização do espaço-tempo de aprender, nessa proposta, situa a leitura, escrita e o brincar na vida das crianças e de que modo se apresenta para a prática do professor. A presente investigação consiste numa pesquisa documental caracterizada pelo procedimento da configuração textual e do paradigma indiciário. Por meio da análise dos Cadernos do Programa constatou-se que o planejamento do processo de alfabetização e ensino-aprendizagem da língua portuguesa é voltado exclusivamente para os eixos constituintes da língua (leitura; produção de textos escritos; oralidade; análise linguística: discursividade, textualidade e normatividade; e análise linguística: apropriação do sistema de escrita alfabética); todos esses elementos contemplam o que se espera que o professor ensine às crianças, ao mesmo tempo, se estabelece que as crianças têm o direito de aprender de modo geral e específico, o que é importante trabalhar em cada ano do ciclo de alfabetização, excluindo-se, assim, as características próprias das crianças de seis anos na organização do espaço-tempo escolar, as manifestações de outras linguagens e sua incorporação nas rotinas escolares, contribuindo para uma desvalorização do brincar e um distanciamento das necessidades infantis. Salientamos que o brincar, principal atividade e direito das

12 Professora Mestra da área de Alfabetização Inicial da Escola de Educação Básica da Universidade Federal de Uberlândia - ESEBA/UFU.

13 Professora Doutora da Faculdade de Educação da Universidade Federal de Uberlândia FACED/UFU e do Programa de Pós Graduação em Educação da Universidade Federal de Uberlândia - PPGED/UFU. 
crianças, está sendo descaracterizado devido às exigências do ensino fundamental. De acordo com a análise empreendida, constatamos a existência de um discurso predominante na orientação das práticas docentes e na regulação dos tempos de aprendizagem das crianças, sustentado no direito de aprender das crianças, definindo o que, como e quando as crianças devem aprender, e por aí naturaliza e padroniza o que, como e quando o professor deve ensinar.

No ano de 2012 foi implementado pelo governo, em parceria com as universidades públicas brasileiras, secretarias de educação e municípios, o PNAIC (Pacto Nacional pela Alfabetização na Idade Certa), com o objetivo de assegurar que todas as crianças estejam alfabetizadas até os 8 anos de idade, ao final do $3^{\circ}$ ano do Ensino Funamental. O PNAIC é uma política pública nacional voltada para a formação de professores alfabetizadores que atuam no $1^{\circ}, 2^{\circ}$ e $3^{\circ}$ ano do Ensino Fundamental e também nas classes multisseriadas.

O processo de alfabetização apresenta-se como assunto prioritário no contexto educacional atual, pois trata-se de uma das prioridades do governo federal em âmbito nacional. Realizar um estudo sobre o PNAIC nos oportuniza compreender as perspectivas e possíveis impasses desse programa, especialmente no que diz respeito às rotinas estabelecidas às crianças, tendo em vista o propósito desse programa que é alfabetizar na "idade certa" a partir do ensino e aprendizagem da leitura e escrita.

Ao tentarmos apreender a proposta do PNAIC sobre os processos de leitura e escrita estabelecidos às crianças, especialmente as do $1^{\circ}$ ano, vimos que não há como fazê-lo se não analisarmos o cotidiano escolar, espaço-tempo do ensino e da aprendizagem.

Buscamos identificar no material do PNAIC como esse programa constrói ou preconiza a organização do cotidiano escolar nas turmas de $1^{\circ}$ ano do ensino fundamental e também compreender como a organização do espaço-tempo de aprender nessa proposta concebe a criança e suas singularidades no processo de ensinar-aprender. Para tanto, as informações aqui produzidas voltam-se para os cadernos do Ano 1, Unidades 1, 2 e 4 que versam sobre "Currículo na alfabetização: concepções e princípios"; "Planejamento escolar: Alfabetização e Ensino da língua Portuguesa" e "Ludicidade em sala de aula", respectivamente. 
De acordo com os propósitos desse estudo qualitativo, optamos pela pesquisa documental por considerarmos essa modalidade como possibilidade para ampliar nosso olhar frente às diferentes faces do objeto a ser investigado e por colocar em destaque a pesquisa documental, uma vez que tal metodologia é "pouco explorada não só na área da educação como em outras áreas das ciências sociais" (LÜDKE e ANDRÉ, 2013: 44).

O caderno da Unidade 2 do PNAIC frisa a importância de se planejar o ensino tendo em vista uma perspectiva ampla do processo que será desenvolvido durante o ano letivo (planejamento anual), bem como a importância de se levar em consideração os microprocessos que revelam um planejamento mais pontual (exemplo: planejamento semanal, mensal); tais aspectos são justificados tendo em vista que "precisamos planejar para fazermos escolhas coerentes, organizar nossas rotinas, ter nossos objetivos delimitados, saber aonde queremos chegar e o que precisamos ensinar aos nossos alunos." (BRASIL, 2012b, p. 07).

Outra perspectiva para a qual conduz o material analisado é o planejamento do processo de alfabetização e ensino/aprendizagem da língua portuguesa, voltado exclusivamente para os eixos direcionadores da língua (leitura; produção de textos; oralidade; análise linguística: discursividade, textualidade e normatividade; análise linguística: apropriação do sistema de escrita alfabética) como orientação estruturante para o planejamento escolar.

Para cada um desses eixos, os Cadernos do PNAIC apresentam quadros de direitos de aprendizagem, que delimitam conhecimentos, capacidades e atitudes a serem desenvolvidos com as crianças no decorrer do $1^{\circ}, 2^{\circ}$ e $3^{\circ}$ anos do ensino fundamental, os quais contemplariam o que se espera que o professor ensine, e estabelecem também o que as crianças têm como direito de aprender, de modo geral e específico em cada ano do ciclo de alfabetização. Diante disso, afirma-se que "para garantir que todas as crianças aprendam a ler e escrever, faz-se necessário traçar direitos de aprendizagem que possam nortear a organização do trabalho pedagógico nas escolas" (BRASIL, 2012a, p.05).

No caderno do ano 1 unidade 1 "Currículo inclusivo: o direito de ser alfabetizado", na seção "Compartilhando" são apresentados os direitos de aprendizagem gerais e específicos para o componente curricular de língua portuguesa 
que devem permear toda a ação pedagógica. De acordo com esse caderno "a definição de direitos de aprendizagem colabora para a discussão acerca do que pode ser priorizado no planejamento do ensino e do que pode ser avaliado" (BRASIL, 2012a, p.22).

Para planejar o ensino com o objetivo de organizar as ações a serem empreendidas durante $\mathrm{o}$ ano letivo em turmas do $1^{\circ}$ ano do ensino fundamental sobressai o trabalho com os diferentes eixos da língua. Por exemplo: No eixo leitura, os usos que fazemos em nossas práticas sociais de letramento devem ser tomadas como base para o ensino e o trabalho na sala de aula com a leitura; no eixo produção de texto o professor deverá promover situações comunicativas para as crianças terem o que dizer e a quem dizer, incentivando a formação da criança produtora de textos para buscar estratégias de escritas. Um exemplo para esse eixo seria as crianças serem incentivadas a escreverem "do jeito que acham que é"; O eixo oralidade aborda a importância de as crianças serem sujeitos capazes de expor, argumentar, explicar, narrar, além de escutar atentamente e opinar, respeitando a vez e o momento de falar; no eixo análise linguística: apropriação do sistema de escrita alfabética deve-se pensar sobre a língua, que possui regras próprias de funcionamento, exigindo conhecimento de sua natureza linguística e de sua estrutura.

É notório que o trabalho pedagógico da linguagem oral e escrita com as crianças precisa ser planejado, discutido, articulado dentro e para fora do espaço escolar, mas, planejar os processos de alfabetização para as crianças do $1^{\circ}$ ano, envolveria planejar sobre os eixos de ensino da língua, de modo a delimitar tempos e espaços de ensino e aprendizagem enfatizando prioritariamente conhecimentos linguísticos, técnicos e escolares da língua portuguesa? Como não envolver ou mencionar em um currículo de $1^{\circ}$ ano a vivência com outras linguagens, por exemplo, as linguagens artísticas e corporal? Nessa análise, buscamos problematizar tais questões a fim de produzir conhecimentos acerca dos limites e das possibilidades das proposições contidas no PNAIC, reafirmando a importância da pluralidade de linguagens na vida das crianças e do rompimento com posturas que se fundamentam em dosagens do que ensinar e do que aprender no "tempo certo", conceitos e posturas que universalizam as práticas pedagógicas e lhes retira infinitas possibilidades de saberes e fazeres no cotidiano escolar. 
O PNAIC defende a construção de rotinas que possibilitem aos professores desenvolver e diversificar atividades no cotidiano escolar, para que os alunos "possam interagir com diferentes textos ao mesmo tempo em que eles são levados a refletir sobre o Sistema de Escrita Alfabética" (BRASIL, 2012b, p. 20).

\begin{abstract}
Desse modo, defendemos que a organização e a sistematização do trabalho pedagógico é muito importante para a aprendizagem dos alunos. A construção de uma rotina escolar que contemple os diferentes eixos de ensino da língua, por meio de um planejamento elaborado com base na realidade de cada aluno e escola, pode favorecer a realização de atividades que ajudem a promover a autonomia e a criatividade dos alunos no mundo da leitura e da escrita (BRASIL, 2012b, p. 20).
\end{abstract}

A partir da defesa do PNAIC em relação ao planejamento e à organização das rotinas constatamos um movimento duplo e ambíguo, o qual produz incerteza e imprecisão conceitual para os docentes, mas também, possivelmente, ausência ou fragilidade de conexão entre o pensar e o fazer de professores. Caso o que se pretenda seja formar professores críticos, criativos e autores de seus trabalhos pedagógicos, entendemos ser importante informar e esclarecer posicionamentos históricos e epistemológicos presentes na história da educação e no trabalho de alfabetizar, pois é o debate sobre diferentes posturas e visões que prevaleceram ao longo da história é que possibilita que professores possam contribuir com a materialização do direito de aprender das crianças.

Identificamos em nossas análises que, por um lado, critica-se com veemência as abordagens positivistas das ciências para a organização do trabalho pedagógico, uma vez que essas se sustentam pela psicologia comportamentalista e pelo tecnicismo no planejamento das rotinas, mas por outro, afirma-se que a partir do trabalho com os eixos estruturantes para o ensino da língua promover-se-á a criatividade e autonomia dos alunos em seus processos de leitura e escrita, tornando as práticas de alfabetização diferentes das que eram realizadas anteriormente, porém, nessa proposta de trabalho se fragmenta a compreensão da língua portuguesa em eixos de ensino, delimitando de maneira predominantemente técnica o que e como fazer docente. 
O discurso apresentado no caderno da unidade 2, Ano 1, materializa-se nas palavras de Telma Leal, apresentadas no referido caderno, quando defende a importância do planejamento para a vida escolar, tendo em vista que

"[...] as rotinas escolares asseguram que alguns "procedimentos" básicos sejam "acordados" entre professor e alunos e que os mesmos já se disponibilizem dentro do espaço temporal e espacial para as tarefas pedagógicas. As crianças aprendem, através dessas rotinas, a prever o que fará na escola e a organizar-se. Por outro lado, a existência dessas rotinas possibilita ao professor distribuir com maior facilidade as atividades que ele considera importantes para a construção de conhecimentos em determinado período, facilitando o planejamento diário das atividades didáticas" (BRASIL, 2012b, p.1920).

Concordamos com a autora na medida em que as rotinas assegurem uma organização do tempo e espaço escolar. Entretanto, Proença (2004) alerta-nos para um fator ideológico que a rotina também assume: o espaço-tempo de aprender a partir das atividades e dos encaminhamentos propostos no processo de ensino e aprendizagem envolve uma razão que se sustenta por meio das prioridades e opções estabelecidas no fazer pedagógico.

A rotina estruturante é como uma âncora do dia-a-dia, capaz de estruturar o cotidiano por representar para a criança e para os professores uma fonte de segurança e de previsão do que vai acontecer. Ela norteia, organiza e orienta o grupo no espaço escolar, diminuindo a ansiedade a respeito do que é imprevisível ou desconhecido e otimizando o tempo disponível do grupo. É um exercício disciplinar a construção da rotina do grupo, que envolve prioridades, opções, adequações às necessidades e dosagem das atividades. A associação da palavra âncora ao conceito de rotina pretende representar a base sobre a qual o professor se alicerça para poder prosseguir com o trabalho pedagógico (PROENÇA, 2004, p.13 grifos nossos).

Questionamos a postura apresentada no caderno em análise e as palavras de Leal (BRASIL, 2012, p.19-20) anteriormente apresentada quanto à ausência da explicitação de que prioridades e opções docentes não são meramente técnicas, mas também políticas. Para exemplificar sua concepção sobre prioridades e opções acerca da rotina, o caderno analisado traz um exemplo de uma professora do $1^{\circ}$ ano do Ensino Fundamental que atua em uma escola municipal da cidade do Recife/PE. A 
professora relata como contempla regularmente em sua rotina "as atividades permanentes, sequências didáticas, projetos didáticos, uso do livro didático (dos componentes curriculares Língua Portuguesa e Matemática) e jogos relacionados à área de linguagem (como os jogos distribuídos pelo MEC) e a outros conteúdos." (BRASIL, 2012b, p. 21).

Por meio do depoimento dessa professora constatamos que em sua rotina semanal possui pelo menos três atividades que acontecem todos os dias, como a leitura deleite, leitura da lista dos alunos e atividades que envolvem a apropriação do sistema de escrita, por exemplo: construção de palavras usando o alfabeto móvel. As atividades que se alternam e que podem, ou não, fazer parte de um determinado projeto ou sequência didática estão presentes também, porém, de forma mais flexível.

O quadro a seguir apresenta e exemplifica a rotina de trabalho de uma semana dessa professora: 


\begin{tabular}{|c|c|c|c|c|}
\hline $\begin{array}{c}\text { SEGUNDA-FEIRA } \\
\text { Dia 28/05 }\end{array}$ & $\begin{array}{l}\text { TERÇA-FEIRA } \\
\text { Dia 29/05 }\end{array}$ & $\begin{array}{l}\text { QUARTA-FEIRA } \\
\text { Dia 30/05 }\end{array}$ & $\begin{array}{l}\text { QUINTA-FEIRA } \\
\text { Dia } 31 / 05\end{array}$ & $\begin{array}{l}\text { SEKTA-FEIRA } \\
\text { Dia 01/06 }\end{array}$ \\
\hline $\begin{array}{l}\text { - Música: Bom dia; } \\
\text { - Registro do } \\
\text { tempo, uso do } \\
\text { calendário (dia, } \\
\text { mês, ano); } \\
\text { - Contagem dos } \\
\text { alunos; } \\
\text { - Escrita da me- } \\
\text { renda do dia (re- } \\
\text { gistro no quadro } \\
\text { para leitura); } \\
\text { - Registro da rotina; }\end{array}$ & $\begin{array}{l}\text { - Música: Bom dia; } \\
\text { - Registro do } \\
\text { tempo, uso do } \\
\text { calendário (dia, } \\
\text { mês, ano); } \\
\text { - Contagem dos } \\
\text { alunos; } \\
\text { - Escrita da me- } \\
\text { renda do dia (re- } \\
\text { gistro no quadro } \\
\text { para leitura); } \\
\text { - Registro da rotina; }\end{array}$ & $\begin{array}{l}\text { - Música: Bom dia; } \\
\text { - Registro do } \\
\text { tempo, uso do } \\
\text { calendário (dia, } \\
\text { mês, ano); } \\
\text { - Contagem dos } \\
\text { alunos; } \\
\text { - Escrita da me- } \\
\text { renda do dia (re- } \\
\text { gistro no quadro } \\
\text { para leitura); } \\
\text { - Registro da rotina; }\end{array}$ & $\begin{array}{l}\text { - Música: Bom dia; } \\
\text { - Registro do } \\
\text { tempo, uso do } \\
\text { calendário (dia, } \\
\text { mês, ano); } \\
\text { - Contagem dos } \\
\text { alunos; } \\
\text { - Escrita da me- } \\
\text { renda do dia (re- } \\
\text { gistro no quadro } \\
\text { para leitura); } \\
\text { - Registro da rotina; }\end{array}$ & $\begin{array}{l}\text { - Música: Bom dia; } \\
\text { - Registro do } \\
\text { tempo, uso do } \\
\text { calendário (dia, } \\
\text { mês, ano); } \\
\text { - Contagem dos } \\
\text { alunos; } \\
\text { - Escrita da me- } \\
\text { renda do dia (re- } \\
\text { gistro no quadro } \\
\text { para leitura); } \\
\text { - Registro da rotina; }\end{array}$ \\
\hline $\begin{array}{l}\text { Roda de conversa } \\
\text { - conversa sobre } \\
\text { o final de semana; }\end{array}$ & $\begin{array}{l}\text { Leitura deleite/ } \\
\text { Ficha de acom- } \\
\text { panhamento dos } \\
\text { livros lidos no } \\
\text { mês; }\end{array}$ & $\begin{array}{l}\text { Leitura deleite/ } \\
\text { Ficha de acom- } \\
\text { panhamento dos } \\
\text { livros lidos no } \\
\text { mês; }\end{array}$ & $\begin{array}{l}\text { Leitura deleite/ } \\
\text { Ficha de acom- } \\
\text { panhamento dos } \\
\text { livros lidos no } \\
\text { mês; }\end{array}$ & \multirow{2}{*}{$\begin{array}{l}\text { Uso do laborató- } \\
\text { rio de Informá- } \\
\text { tica: Jogos didá- } \\
\text { ticos, de acordo } \\
\text { com as necessi- } \\
\text { dades do grupo } \\
\text { ou relacionada ao } \\
\text { que está sendo } \\
\text { estudado (digitar } \\
\text { palavras ditadas } \\
\text { pela professora): }\end{array}$} \\
\hline $\begin{array}{l}\text { Leitura deleite/ } \\
\text { Ficha de acom- } \\
\text { panhamento dos } \\
\text { livros lidos no } \\
\text { mês; }\end{array}$ & $\begin{array}{l}\text { Roda de leitura: } \\
\text { texto informativo } \\
\text { sobre a extinção } \\
\text { de animais; }\end{array}$ & $\begin{array}{l}\text { Projeto didático: } \\
\text { sustentabilidade } \\
\text { e o lixo, reflexão } \\
\text { sobre a poluição } \\
\text { dos rios que } \\
\text { prejudica o habi- } \\
\text { tat dos animais; }\end{array}$ & $\begin{array}{l}\text { Roda de leitura: } \\
\text { Texto instrucional } \\
\text { sobre a brincadei- } \\
\text { ra das cadeiras, } \\
\text { explicitando as } \\
\text { regras (vivência } \\
\text { da brincadeira no } \\
\text { pátio da escola); }\end{array}$ & \\
\hline $\begin{array}{l}\text { Merenda/Recreio } \\
\text { Cantinho da leitu- } \\
\text { ra (livre); }\end{array}$ & $\begin{array}{l}\text { Merenda/Recreio } \\
\text { Cantinho da leitu- } \\
\text { ra (livre); }\end{array}$ & $\begin{array}{l}\text { Merenda/Recreio } \\
\text { Cantinho da leitu- } \\
\text { ra (livre): }\end{array}$ & $\begin{array}{l}\text { Merenda/Recreio } \\
\text { Cantinho da leitu- } \\
\text { ra (livre); }\end{array}$ & $\begin{array}{l}\text { Merenda/Recreio } \\
\text { Cantinho da leitu- } \\
\text { ra (livre): }\end{array}$ \\
\hline $\begin{array}{l}\text { Roda de leitura: } \\
\text { Texto Jacaré } \\
\text { (João Paulo Paes), } \\
\text { interpretaçăo } \\
\text { textual, destacan- } \\
\text { do a problemática } \\
\text { de animais em } \\
\text { extinção. }\end{array}$ & $\begin{array}{l}\text { LD } \\
\text { Português: (no- } \\
\text { mes, brincadeiras } \\
\text { e letras)-cantiga } \\
\text { de roda: ciranda, } \\
\text { cirandinha, iden- } \\
\text { tificaçăo do nome } \\
\text { dos colegas; }\end{array}$ & $\begin{array}{l}\text { Construção de } \\
\text { um mural, a partir } \\
\text { das figuras sele- } \\
\text { cionadas pelos } \\
\text { alunos, destacan- } \\
\text { do caracteristicas } \\
\text { dos animais (duas } \\
\text { patas, quatro } \\
\text { patas, nenhuma } \\
\text { pata): }\end{array}$ & $\begin{array}{l}\text { LD Matemática: } \\
\text { Brincadeira das } \\
\text { cadeiras, identi- } \\
\text { ficando sucessor } \\
\text { e antecessor dos } \\
\text { numerais, conta- } \\
\text { gem e leitura de } \\
\text { imagens; }\end{array}$ & $\begin{array}{l}\text { Produção textual } \\
\text { coletiva com re- } \\
\text { gistro em ficha; }\end{array}$ \\
\hline $\begin{array}{l}\text { Atividade de } \\
\text { apropriação do } \\
\text { SEA: construção } \\
\text { de palavras, uti- } \\
\text { lizando alfabeto } \\
\text { móvel e regis- } \\
\text { tro no caderno } \\
\text { (dupla). }\end{array}$ & $\begin{array}{l}\text { Jogo didático: } \\
\text { Bingo dos sons } \\
\text { iniciais (apresen- } \\
\text { taçăo dos jogos, } \\
\text { explicitando as } \\
\text { regras). }\end{array}$ & $\begin{array}{l}\text { Atividade de } \\
\text { apropriação do } \\
\text { SEA: construção } \\
\text { de palavras, uti- } \\
\text { lizando alfabeto } \\
\text { móvel e regis- } \\
\text { tro no caderno } \\
\text { (dupla). }\end{array}$ & $\begin{array}{l}\text { Jogo didático: } \\
\text { Caça-rimas (apre- } \\
\text { sentação dos } \\
\text { jogos, explicitan- } \\
\text { do as regras). }\end{array}$ & $\begin{array}{l}\text { Hora do brinque- } \\
\text { do (carrinhos, bo- } \\
\text { necos, bonecas, } \\
\text { joguinhos). }\end{array}$ \\
\hline
\end{tabular}

Fonte: (BRASIL, 2012b, p. 26).

A partir das concepções defendidas e do exemplo indicado pelo PNAIC sobre a organização do trabalho pedagógico é relevante tecermos algumas reflexões sobre 
as rotinas das crianças nas turma de alfabetização, especialmente, nas turmas de $1^{\circ}$ ano.

Constatamos que o foco da rotina apresentada no caderno em questão está voltado para a linguagem oral e escrita privilegiando vários aspectos que o PNAIC sugere para alfabetizar as crianças, em detrimentos de outros, linguagens artísticas e brincadeiras, por exemplo: o trabalho especifico com a alfabetização é realizado de forma sistemática; atividade permanente com a leitura deleite é assumida; todos os dias os alunos são levados a refletir sobre as unidades menores das palavras por meio dos gêneros textuais; os jogos didáticos são voltados para a exploração de rimas, sons iniciais e trabalho com escrita das palavras; utilização do livro didático de língua portuguesa e de matemática; atividades voltadas para o sistema de escrita alfabética (SEA) para que os alunos pensem constantemente sobre a relação som-grafia.

A maneira como esse exemplo de rotina para $01^{\circ}$ ano do ensino fundamental é apresentado nos inquieta sobremaneira pela ausência de características próprias das crianças, nessa faixa etária, em relação ao modo de organização do tempo e espaço escolar. Acreditamos que o planejamento de uma rotina envolve, como já comentamos anteriormente, prioridades e opções dos docentes, por exemplo, o brincar como atividade inerente à infância, porém na organização indicada pelo Programa é situado no último horário, do último dia da semana, fato que não o torna prioridade e sim uma espécie de compensação, na medida em que as crianças devem realizar primeiro todas as outras atividades previstas.

Sendo assim, chamamos a atenção para algo não mencionado no caderno "Ludicidade na sala de aula", e que está sendo descaracterizado: o brincar das crianças, a prática que as crianças realizam de forma plena, inclusive as crianças de seis anos que estão sendo desprovidas dessa dimensão, devido às exigências do ensino fundamental; o brincar, no Caderno, refere-se às atividades lúdicas, às brincadeiras e aos jogos como ferramentas voltadas para o ensino dos conteúdos. Tais estratégias são importantes e contribuem para o ensino e a aprendizagem, propiciando interações das crianças com os conhecimentos de maneira prazerosa. No entanto, "quando tais atividades são compreendidas apenas como recursos, perdem o sentido de brincadeira e, muitas vezes, até mesmo seu caráter lúdico, assumindo muito mais a função de treinar e sistematizar conhecimentos” (BORBA, 2007, p. 43). 
Observamos que no PNAIC concebe-se uma função restrita para o brincar; na proposta do PNAIC projeta-se também uma representação restrita de criança e de infância. Inquieta-nos, nesse caso, o lugar restrito da infância no processo educativo tendo em vista que prevalece uma visão adultocêntrica do aprender, valorizando aspectos técnicos da alfabetização em detrimento do reconhecimento da infância como diversidade nos modos de ser, o que se expressa numa necessidade de experimentação com múltiplas linguagens para a concretização do aprendizado escolar das crianças. Delimitar uma rotina para as crianças, em especial para as de 6 anos, requereria contemplar singularidades de crianças reais, produtoras de cultura, e seus direitos, principalmente o de aprender e o de brincar. Nesse sentido, ratificamos as palavras de Hermes (2015), ao defender esse direito no currículo do ensino fundamental:

Entre todos esses direitos apresentados na materialidade do Programa, parecia pertinente, sim, pensar numa infância brincante para as crianças. Então, inspirada na filosofia de Bachelard (1988), encontrei o conceito de infância, "estado da alma". Assim, pensando numa infância brincante, trato de trazer mais um "direito" a ser incluído no currículo e nas práticas de alfabetização/letramento: o "direito ao brincar". Este direito é das crianças ao passo que nós gestores podemos contribuir para uma infância brincante, crianças que necessitam ser pensadas em sua condição [...]. (HERMES, 2015, p. 89).

Nesse sentido, identificar como as formas de brincar e as expressões lúdicas e livres das crianças apresentam-se nas rotinas, desvelam posturas e concepções sobre a infância poderiam ser mais valorizadas no processo educacional, o que requereria além da formação docente preconizada no PNAIC, a criação de condições para que escolas possam continuar o trabalho feito nesse programa por meio da efetivação de um processo de formação continuado e em serviço de docentes. A rotina que defendemos visualiza, valoriza e trabalha a linguagem oral e escrita, mas, sobretudo, abre-se para o reconhecimento e incorporação ao trabalho educativo com infâncias diversas de sujeitos sociais diferentes. Sujeitos que se constituem nas relações sociais, na produção da cultura e no brincar. Sujeitos que se expressam de forma plural em múltiplas linguagens. 
Sendo assim, constatamos na proposta do PNAIC uma ausência de incentivo para o trabalho docente com outras linguagens, além da língua portuguesa, e até mesmo os para outros componentes curriculares que se fazem presentes nesse ano de ensino, por exemplo, educação física, arte, música. Uma proposta coerente e significativa para as crianças necessita criar meios para que os professores possam promover uma relação prazerosa e significativa entre ensino e aprendizagem, por isso destacamos a importância de se valorizar as brincadeiras e os brinquedos (o que não consta como material do PNAIC destinados às escolas), os jogos simbólicos, o movimento, as expressões artístico-culturais, tais como teatro, a música e a dança, enfim, trata-se de valorizar as inúmeras manifestações de linguagens e sua incorporação nas práticas de planejamento das atividades escolares diárias.

Verificamos que a proposta do PNAIC disponibiliza aos professores uma matriz curricular que organiza os tempos escolares, dosando a aprendizagem das crianças de modo a introduzir, aprofundar e consolidar em cada uma delas e durante os três primeiros anos do ensino fundamental as capacidades e os conhecimentos referentes ao componente curricular da língua portuguesa. Nesse sentido, o formato desse Programa é totalmente prescritivo, orientado por uma pedagogia que normatiza a linguagem, um modelo educativo que busca desenvolver o ensino visando a uma aprendizagem controlada e marcada por níveis de conhecimento de acordo indiretamente com as idades das crianças, mesmo mencionando poucas vezes de maneira direta a questão da idade cronológica das crianças. Diante desse cenário, podemos inferir também que existe uma concepção de aluno ideal, de criança modelo que transitará no ciclo de alfabetização, perfazendo seu caminho de aprendizagem ano após ano, concretizando seu direito de aprender de acordo com conteúdos determinados.

Aos professores alfabetizadores é necessário organizar um planejamento a partir dos eixos da língua portuguesa apresentados pelo PNAIC por meio de sequências didáticas, projetos didáticos, jogos pedagógicos, contemplando a alfabetização na perspectiva do letramento e possibilitando o avanço nas aprendizagens da linguagem oral e escrita pelas crianças. Para tal objetivo, devem aprender a organizar e favorecer ações pedagógicas que permitam às crianças, gradativamente, se alfabetizarem até $\circ 3^{\circ}$ ano do Ensino Fundamental. 
Diante do que analisamos, a partir do material produzido para o PNAIC, compreendemos que pensar a própria criança - considerando processos sociais que caracterizam seu momento de vida e seus processos singulares, presentes em diferentes culturas e contextos sociais, suas capacidades físicas, cognitivas, estéticas, éticas, expressivas e emocionais, proporcionando-lhe um ambiente rico em interações e situações de desafios, no qual pode ampliar gradativamente a compreensão acerca de si mesma e do mundo - continua sendo um desafio para a alfabetização, o qual foi parcialmente enfrentado pelo Programa.

A superação de rotinas estéreis, do ponto de vista das especificidades infantis torna-se pertinente na medida em que favorece uma ação pedagógica respaldada em uma visão integrada acerca do desenvolvimento infantil, respeitando as peculiaridades de cada criança e oportunizando, de fato, situações de aprendizagem significativas e prazerosas.

Brincar é, sem dúvida, uma forma de aprender, mas é muito mais que isso. Brincar é experimentar-se, relacionar-se, imaginar-se, expressarse, compreender-se, confrontar-se, negociar, transformar-se, ser. Na escola, a despeito dos objetivos do professor e de seu controle, a brincadeira não envolve apenas a atividade cognitiva da criança. Envolve a criança toda. É prática social, atividade simbólica, forma de interação com o outro. Acontece no âmago das disputas sociais, implica a constituição do sentido. É criação, desejo, emoção, ação voluntária (FONTANA \& CRUZ, 1997, p. 139).

Por isso torna-se imprescindível garantir na rotina escolar de todas as crianças, tempo e espaço para brincar; o brincar sendo entendido aqui não como recurso pedagógico, mas sim como prática inerente à infância e que se constitui de múltiplas linguagens. Identificamos, portanto, que por mais que o PNAIC tente combater e criticar visões e práticas educativas tecnicistas prevalece em suas orientações a visão e o incentivo para a criação de uma rotina escolar predominantemente tecniscista e tecnicizante, centrada nos eixos estruturantes da língua portuguesa, conduzindo à fragmentação da linguagem.

Conjecturamos, na contramão dessa perspectiva, que disciplina e didatiza o brincar, outros modos de pensar os processos de escolarização na alfabetização inicial, envolvendo, nessa dimensão, espaços e tempos para a vivência das múltiplas linguagens, alargando o tempo das experiências em linguagens da criança. Tal tempo 
não se refere ao cronológico, linear e evolutivo que limita e fragmenta as aprendizagens destinadas à leitura e à escrita com a pretensão de se alfabetizar na "idade certa". Falamos de um tempo amplificado para as experiências da própria condição de ser criança, um tempo em que a criança, tomada com seu modo de ser e de estar na relação com o mundo, expressa-se nas linguagens, no brincar, em sua inteireza.

\section{REFERÊNCIAS}

BORBA, Ângela Meyer. O brincar como forma de ser e estar no mundo. In: BEAUCHAMP, Jeanete; PAGEL, Sandra Denise; NASCIMENTO, Aricélia Ribeiro do (orgs). Ensino Fundamental de Nove Anos: orientações para a inclusão da criança de seis anos de idade. Brasília: FNDE, Estação Gráfica, 2007.

BRASIL. Ministério da Educação. Secretaria de Educação Básica. Diretoria de Apoio à Gestão Educacional. Pacto nacional pela alfabetização na idade certa: Currículo na alfabetização: concepções e princípios. Ano 1: Unidade 1. Brasília: MEC, SEB, 2012a.

. Ministério da Educação. Secretaria de Educação Básica. Diretoria de Apoio à Gestão Educacional. Pacto nacional pela alfabetização na idade certa: Planejamento escolar: alfabetização e ensino da língua portuguesa. Ano 1: Unidade 2. Brasília: MEC, SEB, 2012b.

. Ministério da Educação. Secretaria de Educação Básica. Diretoria de Apoio à Gestão Educacional. Pacto nacional pela alfabetização na idade certa: Ludicidade na sala de aula. Ano 1: Unidade 4. Brasília: MEC, SEB, 2012c.

FONTANA, Roseli, CRUZ, Nazaré. Psicologia e trabalho pedagógico. São Paulo: Ed. Atual, 1997.

HERMES, Rosméri. Docências, crianças e políticas de alfabetização/letramento: entre capturas e possibilidades nas escolas municipais de Arroio do Tigre/RS. $121 f$. Dissertação (Mestrado em Educação), Universidade de Santa Cruz do Sul, Santa Cruz do Sul, 2015. 
LÜDKE, Menga, ANDRÉ, Marli E. D. A. Pesquisa em educação: abordagens qualitativas. 2. ed.; Rio de Janeiro: E.P.U., 2013.

PROENÇA, Maria Alice de Rezende. A rotina como âncora do cotidiano na Educação Infantil. Revista Pátio Educação Infantil, Porto Alegre, n. 4, p.13-15, 04 abr. 2004. 